\title{
Considering Entrepreneurship? Here's a Pre-Launch Checklist
}

\author{
Tim Tivis (Pinnacle Training Group, LLC)
}

KEYWORDS: Entrepreneurship.

Picture this: You are sitting at your desk four o' clock on a Friday afternoon. Your mind is racing. Surely there must be more to this work thing than the nine to five. I have dreams, goals and I am really getting burnt out here. Something has to give. Is it time for me to take the leap and start my own thing?

If you are thinking this way, you are not alone. Many people come to these crossroads. My story however, is much different because my journey into starting my own thing began right out of college. I acquired my insurance and securities licenses, signed an office lease, put my shingle on the wall and started prospecting business on day one!

Regardless of how you reach your defining moment, I believe some common factors lead each of us to the decision to venture out and claim our piece of the "entrepreneurial dream." BUT, before you board and set sail on your personal journey, it is important to take a serious look at your vessel, your resources and in particular the resolve to reach your destination. Here's a pre-launch checklist.

\section{Reality Check}

Not to start out gloom and doom, but the reality is that the odds are not in your favor. The journey of entrepreneurship is not a made-for-television movie, where in a two-hour time frame someone goes from having nothing to owning a successful corner café or launching a globally accepted new product or service. According to an October 2014 article in the Gallup Business Journal entitled "Why So Many New Companies Fail During Their First Five Years," half of all new start-ups fail in the first five years and $80 \%$ of these failures happen in the first year.

The good news however is that this same research discovered that the success of a new business had a significant amount to do with the person (that's you and me) starting the business. After studying 4,000 entrepreneurs, the researchers found that the entrepreneur's talent and drive had the biggest impact on whether a venture thrived or failed.

So before you embark on your journey, make an honest assessment of how much you want it and whether you have the talent and drive to see you through hard times. Then be prepared to work like never before. Success is possible, but it MUST be viewed for what it is from the very beginning!

\section{Check Your Map}

It is critical you have a well-laid-out plan before you start your journey. Hit and miss can destroy you! This does not mean that you have everything figured out...it simply means you have a plan and a purpose to guide you through all the "learning moments" you will experience. Your map must be current and provide all the necessary data and resources available regarding your journey. These include your capital, your product, your market, your competition, your support system, people and any legal issues, just to name a few. Imagine beginning a trip to an unfamiliar destination with an outdated or incomplete navigation guide. Starting a new venture with such inadequate guidelines can be just as perilous and frustrating.

\section{Check Your Stake In the Game}

Knowing that your personal value is significant to your outcome, how would you answer the following questions? What is your invested interest in the outcome? Does it matter personally and emotionally as well as financially if you succeed or fail? One of the key ingredients in determining the outcome of a successful business is the level of ownership in the results. Naturally, entrepreneurs who are highly invested get more involved in influencing the outcome. To gauge the size of your stake in your dream, answer the following statements.

1. The most important person I answer to regarding my 
performance, regardless of employment status, is me.

2. It really hurts when I fall short, and I will do everything in my power to fix it as soon as possible.

3. I experience real joy and satisfaction in great outcomes for others and for myself

4. I am constantly on my own, striving to be more productive, and I am in a constant learning mode

\section{My work matters to me beyond the paycheck}

If you are able to agree unconditionally with the statements above, then you possess the attitude and approach as well as the commitment to being highly invested in the outcome. Coupling this with a genuine sense of urgency to succeed will be a great catalyst to launching you in the right direction on your entrepreneurial journey.

\section{Check Your Creativity Meter}

Remember when you were a kid and how easy it was to dream? To take a simple blank pad and a box of crayons, and based on the choices you made, draw your masterpiece? Remember how proud you were of your creation and how you could not wait to share it with others and then be recognized and accepted for your performance? When was the last time you felt like that? If you have not experienced that since your childhood, it would be a great idea to check your creativity meter before you start this journey. These built-in desires we longed for as youth -- to build or create something and proudly sign our name to it -- are still there! I would go so far as to say they are a "MUST-HAVE" for your entrepreneurial trip. We just need to rediscover, develop and re-ignite them.

If your journey is to be a successful one, you must possess the abilities to be creative and think beyond the status quo. One of the greatest attributes of successful entrepreneurs is their ability to create a distinction between themselves and their competition. This takes creativity. Henry Ford revolutionized the automobile industry when he dreamed of building a car that was affordable to everyone. He further expanded this by developing the first of its kind assembly line, which influenced the development of those used today. He changed the world...and it all began with one creative thought!

\section{Check Your Decision Making}

How do you make decisions? Are they painstaking adventures, off the cuff, well-thought-out or perhaps a combination of both? Regardless, the decisions you make are the transparent results of what your business looks like now and what it will look like in the future.

As I interviewed entrepreneurs from various industries, it became clear that each fully understood they would live with the outcomes of their choices. If things were going great, it was a result of choices made and implemented that led to the successes. If things were not where they wanted them to be, once again a choice to do or not do something could be clearly identified.

It is critical you become aware of how you make decisions. They create the experiences that influence your habits and your actions. I cannot stress enough the importance of checking your approach and your implementation of decision making.

\section{Check Your Motivation Level: Trial or True Ownership}

How serious are you? Gut check time. Did the idea to launch a business come to you on a whim, because you had a bad day? Has this desire been burning inside of you and causing you to lose sleep...is it "do or die"? Do you have a trial ownership mentality or a true ownership mentality? When things get tough, do you stick with your decision, or are you looking for the box and the shipping instructions to send back what you ordered? In your mind, are you at the point where you must be committed and failure is not an option? A trial ownership mentality can be dangerous because it takes on the attributes of true ownership at the beginning of the process. These are serious questions, and, as indicated in the study referenced above, your motivation must be an "all-in" approach. You need every resource possible to launch successfully...and sustain it!

The key to motivation is that it must be yours...personally. A supervisor, employer or spouse can push you to perform by suggesting you "pick it up a little," but without a personal incentive to act and achieve motivation is just another buzzword everyone likes to talk about.

Once your motivation is solid and sincere, develop your skills and abilities to form great habits and attitudes. Refine your motivation into its proper perspective. This 
simply means doing the right things with the right people, at the right time. Surround yourself with positive influences, and by all means seek help and pursue all opportunities. You must keep your motivation alive, whatever it is -- because once it's gone, the dream won't be far behind.

\section{Conclusion}

While many factors determine whether an entrepreneur is successful, the most important thing l've learned -from my own experiences and others' -- is that entrepreneurship is a journey that requires good preparation. I have been in business for myself for 31 years, and while I do not claim to know everything, I can say assuredly the checklists and the decisions made three decades ago still guide me today. If you can glean any insight that will equip you for success on this incredible lifelong journey, my work is done and I gladly conclude by saying "Welcome Aboard!"

This writing is based upon Tim Tivis's book "Unleash Your Entrepreneur Factor". (https://www.amazon.com/Unleash-Your-EntrepreneurFactor-Exponential-ebook/dp/B00YEZM8PM) 